Aus dem Physiologischen Institut der Medizinischen Faloultä̈t Okayama.

(Vorstand: Prof. Dr. S. Oinuma)

\title{
Experimentelle Studien über die Korrelation zwischen Vitamin C und Prothrombin in Blutplasma.
}

\section{(I. Mitteilung.)}

Über die Veränderung des Prothrombins in der Blutplasma bei skorbutischen Meerschweinchen.

Von

Nobutada Tamao.

Eingegangen am 15. Juli 1942.

Verfasser mass die Gerinnbarkeit und den Prothrombingehalt des Blutes bei den künstlich erzeugten skorbutischen Meerschweinchen, und kam zu folgenden Schlüssen.

1) Die Gerinnungszeit des Blutes verlängert bei den skorbutischen Meersch weinchen.

2) Dies beruht auf die Verminderung des Prothrombingehaltes im Blut bei den skorbutischen Meerschweinchen. (Autoreferat)

\section{6.}

$612.015 \cdot 3$

\section{本邦産食用茸浸出液二就テノ アアチールコリン」合成問題}

岡山圈科大攻生理學教空 (主任生沼教授)

副手赤枝㭲

[昭和 17 年 9 月 8 日受樀]

\footnotetext{
茅 1章、緒 言

量二余へ各種食朋萍浸出派中ノ「アセチールコ

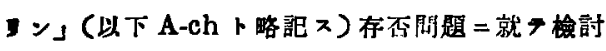
そ「からたけ」中二ハK「イォン」ノ外 $=\mathrm{A}-\mathrm{ch}$ 様

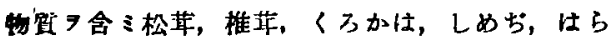

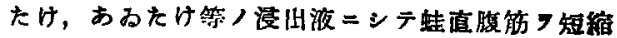

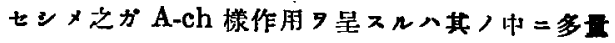

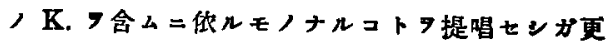

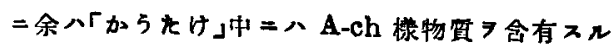
點二鑑ミ之ガ「アセト醋酸」ト結合ンテ起ルA-ch
} 
合成問题ノ可能性二就テ研究ン聊カ考察 ルア以テ妓二概說スル所フラントメ，借而 A-ch

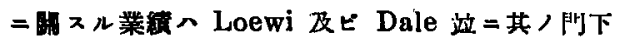

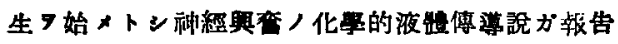

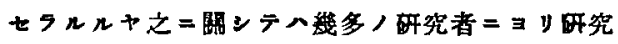

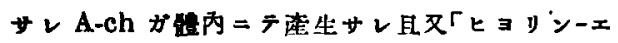

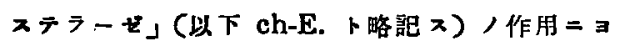

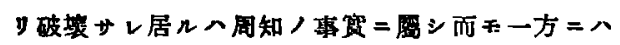
Eserin ガ ch-E. /作用 9 抑制之且 Eserin /作用

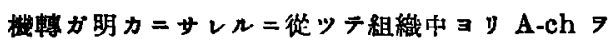
分離抽仙ス几方法モ改良サレ今日殆ド總テノ生能 粗機中

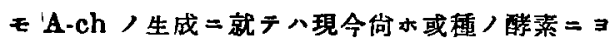
几合成卜云七或八刀單二化學的二結合せンモノカ 分離スルト云へレ今向水諭議區々ニシう研究悬路 ノ中心フナスモノナリ，然ラパA-ch ガ動物䯠内

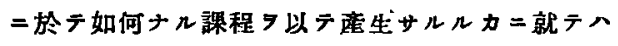
確論ナク成書 $\boldsymbol{\nabla}$ 繙ク = Stedman E. and Stedman E. ${ }^{13)}$ 1)雨氏 $\sim A$-ch $\sim$ Cholin r Acetoessigeäure ヨリ合成サレ得ルト云フ假說ノモト $=\mathrm{A}-\mathrm{ch}$ ガ動

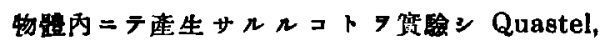
Tennedbaum, Wheatley ${ }^{13}$ 等 $=\exists$ y Acetoese日iggāure 这ビ其誘導物ノ若干ノモノ

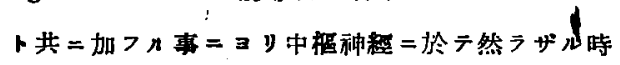

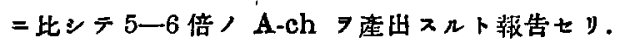

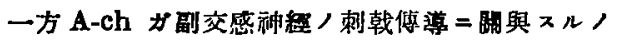

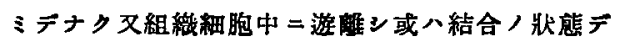
存在スルコトモ㷺 $=$ Corteggiani ${ }^{3}$; Corteggiani, gautrelet, Kaswin and Mentzer')代ビ Correggiani, Gautrelet, Gentil and Kaswin ${ }^{5}$ 管务妇 ンク唱ー居ル所ナリ。然ラバ茸数中， Cholin =

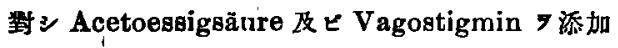

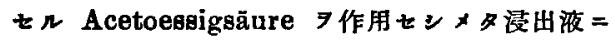

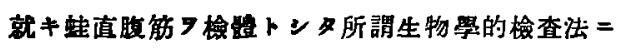

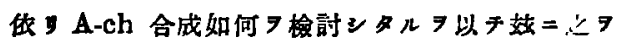
報告 $ᄌ$ 。

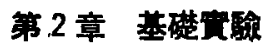

第 1 筫佊检材料及ビ其ノ作製

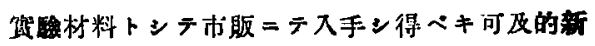

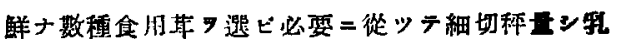

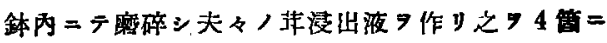
分颣七り，即子

a) 材料 $5 \mathrm{~g}+$ Ringer 氏液 $20 \mathrm{cc}$

b) 材料 $5 \mathrm{~g}+$ Vagostigmin-Ringer 液 $20 \mathrm{cc}$

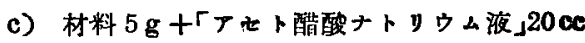

d) 材料 $5 \mathrm{~g}+$ Vagostigmin-Ring $5 \mathrm{cc}+\mathrm{r}$ セト醋酸ナトリウム液」 $15 \mathrm{cc}$

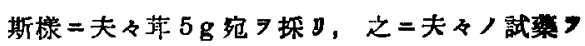

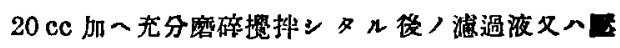

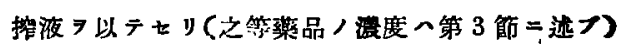

第 2 節 使用椠品

1) Acetylcholin (以下 A-ch 1 略部 $\pi$ )

之一 Roche 製 A-ch =ンテ蒸溜水 $=$ テ 1000 倍

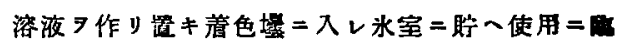
ミ Ringer 氏液ニテ稀釋シテ用フル事トせり。

2) Vagostigmin (以下 Vag. r略記 $ᄌ$ )

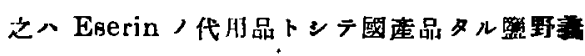

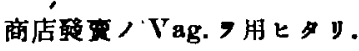

3）「アセト醋酸エチル」ト菏性曹達/ $1 \mathrm{~mol}$

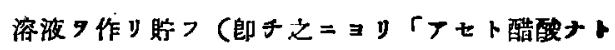
リウム」ガ生ズ) Natrum Acotoacetate

4) Ringer 氏液

$\mathrm{NaCl} 6.0 \mathrm{~g}, \mathrm{CaCl}_{2} 0.2 \mathrm{~g}, \mathrm{KCl} 0.1 \mathrm{~g}, \mathrm{NaHCO}_{3}$ $0.1 \mathrm{~g}$ 刃水道水 $1000 \mathrm{cc}=$ 溶解セシモノ

第 3 節、芼品, 稀釋

1) Vagostigmin 稀釋

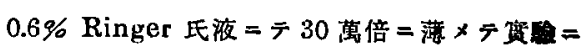
啮 $\pi$.

2) Acetylcholin 稀釋

$0.6 \%$ Ringer 氏液 $=\overline{7}$ 概 $* 1: 2 \times 10^{6}, 3 \times 10^{6}$,

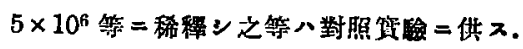


3）「アセト醌酸エチ几」及ビ苛性拍達ノ１ mol 混和液, 稀稗

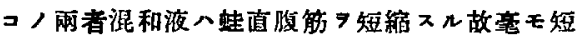
缩をザ几迄稀䆁 ス。即千室溫 $17-18^{\circ} \mathrm{C}=$ テ 30 倍

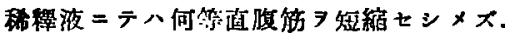

第 4 節 A-ch /定量方法

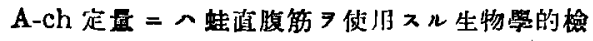

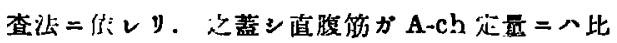
的正確デフリ，简便デモナリ， ス. A-ch $=\Xi ル$ 短編ヨリ，恢復ガ速カナルコトハー般二認ィラレ タルシ以テナリ (Beznak'1), Scheiner $\left.{ }^{12}\right)$ 先炑筋

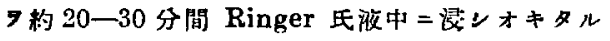

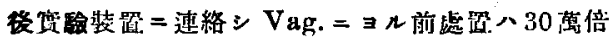

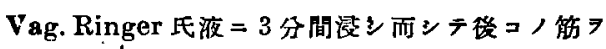
$1: 2 \times 10^{6}-1: 3 \times 10^{6}$ A-ch. Ringer 液ニ浸シテ

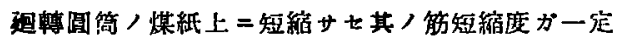

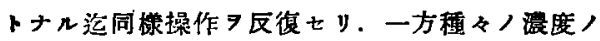

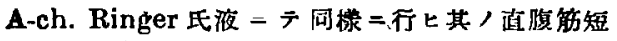
缩 $三$ 比較女り。

第 5 節 䒠比類中，Cholin，證明 $(\mathrm{CH} 3)_{3}=\mathrm{N} / \mathrm{OH}_{2}-\mathrm{CH}_{2}-\mathrm{OH}$

抑々Cholin 一展ク生物界二存就技植物和二

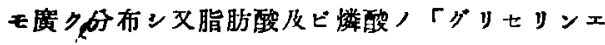
ステル」トンテLecithin 就中植物中 Cholin 分布 $=$ 關ンテハ䭛 $=$ Kiessel's)

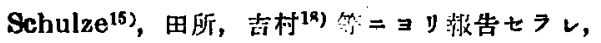
吉村，田所八椎萃中 C Cholin 9 證明七り Cholin 八沃度沃度加里，沃度答制加里 ニンテ余八Rosenheim's Peliodide Test(Hamk ${ }^{7}$ Practical Physiol. Chem. P. 374) $=$ э y 2, 3 莎

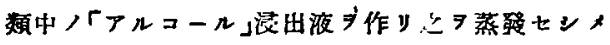

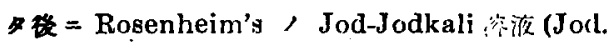
2.0 g. Jodkali 60 g. $\rightarrow \mathrm{H}_{2} \mathrm{O} 100 \mathrm{cc}=$ 溶储七シ * タモつア扣フレベ褐色板狀, Cholin Prism

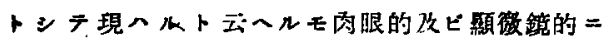
モ䇥明困雅ナリキ，份ホコ，Cholin Prism 一

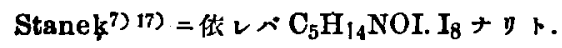

\section{第3 章 䀦驗成綪站二考按}

第 1 節 A-ch 合成八打能ナ・゙

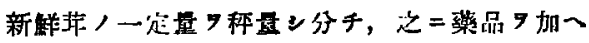

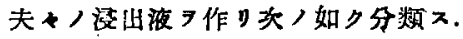

a) 荠 5 g. $+0.6 \%$ Ringer 液 $20 \mathrm{cc}$

b) 莎 5 g. + Vag. Ringer 淮 $20 \mathrm{cc}$

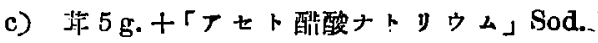
Acetoacetate $20 \mathrm{cc}$

d) 萍 5 g. + Vag. Ringer 掖 5 cc+Sod. Acetoacetatae $15 \mathrm{cc}$

(a), (b), (c), (d) ，各\& =於宁㮌次 $=$ 作製

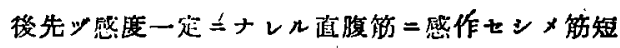

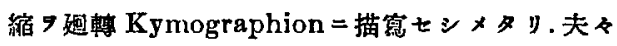

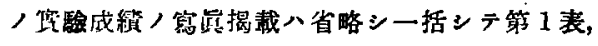
2 表攻ビ代表的ナモノンッキ1例 9 第 1 圆圆 =揭 载ス. 第 1,2 表二示ス如ク何レノ浸出液 $=$ 㓋テモ

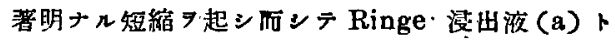
Vag. Ringer 唛出液 $(b)$ 卜間 $=$ 殆 ノ差り認メズ且又(a)液十血清モ「からたり」き除

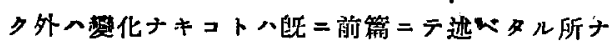
リ. 而シテ就中 (c)ナル Nat. Acotorcetate 浸 山液化ビ Vag. 添加せル (d) ナル Vag. Sod. Acetoacetate 浪出液八他，(a)，(b) '=比短

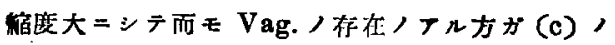

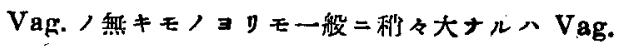
/存在如何が A-ch，淙生如何=關與スルモノト

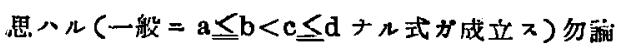
「アせト酷酸ナトリウム」及ヒVag. Ringer 波八 何レモ直腹筋 7 短縮七ンメ又迄二稀程ンナルす以

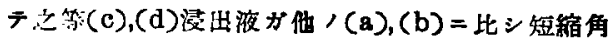

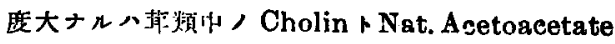
ト合成シテ筋短維曲線二對シ若ン A-ch 梂二作用 センモノトスレベュ（c）液 $=\mathrm{A}-\mathrm{ch}$ ，破䘫醇素 フ合有スル血清 八消隇セザベカラズ，郎手第 1 表，第 2 㤗二示 ス如ク，(c) 液 $10 \mathrm{cc}=$ 血清 $0.7-1.0 \mathrm{cc}$ 名加一同時 =對照トシテー方 $1: 3 \times 10^{6}-1: 4 \times 10^{6} \mathrm{~A}-\mathrm{ch}$ ， 


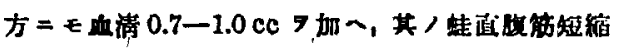

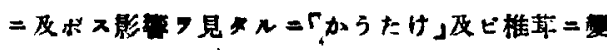

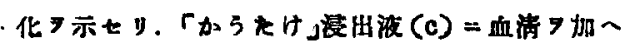
夕所 10 分榙基稳トナス角度八䄪70度ナリンモ，

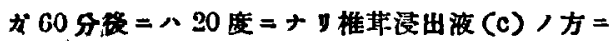

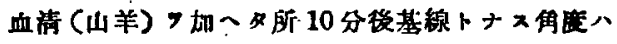
53度ナリンモノガ 60 分铃ニハ科々減少ンテ 43 度 トナレリ，斯ル整化ハ「からたけ」ノカガ著ンク椎

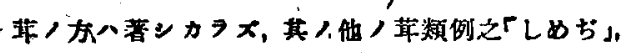
「おるたけ」「はらたけ」, 松荫等つ(c)液二血清

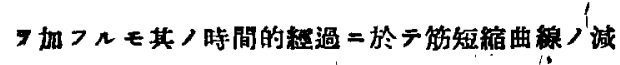

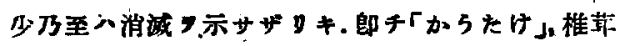

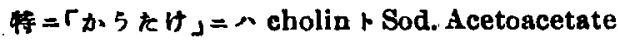

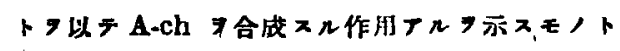

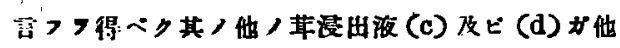

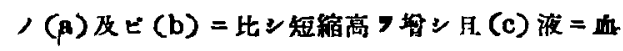

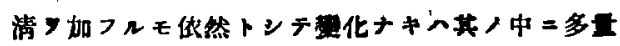

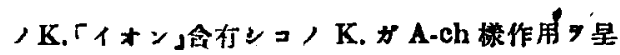
ンタルモノデル.

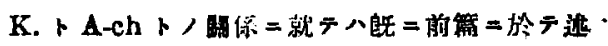
ヘシ所ナルが Mendel ${ }^{10)}$ の派モ K. ハ ch-E. /作

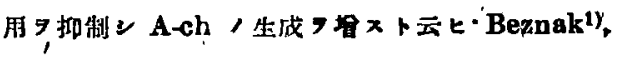
Feldberg and Guimarig6) 矮へK. A-ch 八遊離

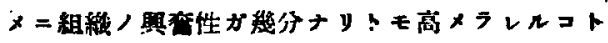
!も考へラル。既二述へタ样こ「からたけ」中， cholin $\vdash$ Sod. Acetoscetate ト 7 以直腹解 $=$

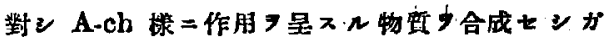
Stedman E. \& Stedman E. 18) 14)雨氏八既 = A-ch

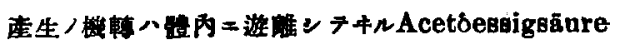
ト cholinト/合成二依りナ生ズルナタント云へ y.

筞 1 表 食用菆浸出液中 Cholin ノケアセト醋酸ナトリウム」合成二

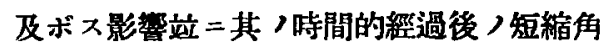

Z.T. $12-14^{\circ} \mathrm{C}$

$\mathrm{PH}=6.4 \longrightarrow 6.6$

\begin{tabular}{|c|c|c|c|c|c|c|c|c|c|c|c|c|c|}
\hline \multirow{2}{*}{\multicolumn{2}{|c|}{ 被檢組絽 }} & \multirow{2}{*}{$\begin{array}{l}\text { 抽出 } \\
\text { 液人 } \\
\text { 箃法 }\end{array}$} & \multirow{2}{*}{$\begin{array}{l}\text { 處 } \\
\text { 埴 } \\
\end{array}$} & \multirow{2}{*}{ 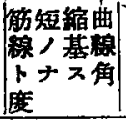 } & \multirow{2}{*}{ 䆀過時間 } & \multicolumn{7}{|c|}{ 挺過時間後，短縮角 } & \multirow{2}{*}{ 學 } \\
\hline & & & & & & $0^{\prime}$ & $10^{\prime}$ & $20^{\prime}$ & $30^{\prime}$ & $40^{\circ}$ & $50^{\prime}$ & $60^{\prime}$ & \\
\hline $\begin{array}{l}\text { } \\
\vdots \\
\hbar \\
\wp\end{array}$ & $\begin{array}{l}\text { (a) } \\
\text { (b) } \\
(\mathrm{c})\end{array}$ & 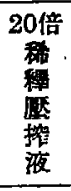 & 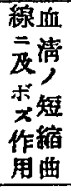 & $\begin{array}{l}62^{\circ} \\
63^{\circ} \\
72^{\circ} \\
\gamma\end{array}$ & 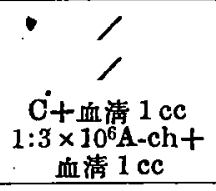 & . & $70^{\circ}$ & $\begin{array}{l}68^{\circ} \\
62^{\circ}\end{array}$ & $60^{\circ}$ & $35^{\circ}$ & $32^{\circ}$ & $\begin{array}{r}20^{\circ} \\
9^{*}\end{array}$ & $\begin{array}{c}\text { Hydnumaspra- } \\
\text { tum }\end{array}$ \\
\hline $\begin{array}{l}\text { L. } \\
\text { b } \\
\text { ち }\end{array}$ & $\begin{array}{l}\text { (a) } \\
\text { (b) } \\
\text { (c) } \\
\text { (d) }\end{array}$ & 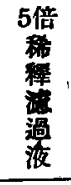 & 上 & $\begin{array}{l}60^{\circ} \\
60^{\circ} \\
65^{\circ} \\
65^{\circ}\end{array}$ & $\begin{array}{c}/ \\
\mathrm{C}+\text { 血清 } 0.6 \mathrm{cc} \\
1: 4 \times 10^{6} \mathrm{~A}-\mathrm{ch}+ \\
\text { 血清 } 0.6 \mathrm{cc} \\
\end{array}$ & & $\begin{array}{l}65^{\circ} \\
43^{\circ}\end{array}$ & $65^{\circ}$ & $\begin{array}{l}66^{\circ} \\
20^{\circ}\end{array}$ & $66^{\circ}$ & $\begin{array}{r}67^{\circ} \\
0^{\circ}\end{array}$ & & $\begin{array}{c}\text { Tricholoma- } \\
\text { shimeji }\end{array}$ \\
\hline $\begin{array}{l}\text { は } \\
\vdots \\
\text { た } \\
\ddots\end{array}$ & $\begin{array}{l}\text { (a) } \\
\text { (b) } \\
\text { (c) } \\
\text { (d) }\end{array}$ & 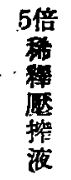 & 上 & $\begin{array}{l}36^{\circ} \\
36^{\circ} \\
38^{\circ} \\
57^{\circ}\end{array}$ & $\begin{array}{c}/ \\
\mathrm{C}+\text { 血清 } 0.5 \mathrm{cc} \\
1: 3 \times 10^{\circ}-\mathrm{ch}+ \\
\text { 血清 } 0.5 \mathrm{cc}\end{array}$ & & $\begin{array}{l}36^{\circ} \\
50^{\circ}\end{array}$ & $36^{\circ}$ & $34^{\circ}$ & $\begin{array}{l}34^{\circ} \\
12^{\circ}\end{array}$ & $\begin{array}{r}35^{\circ} \\
0^{\circ}\end{array}$ & & $\begin{array}{c}\text { Psalliota } \\
\text {, campestris }\end{array}$ \\
\hline
\end{tabular}

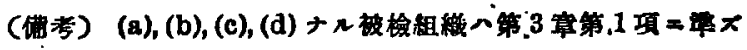




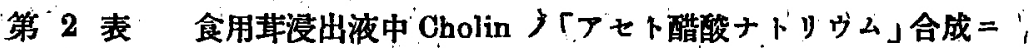

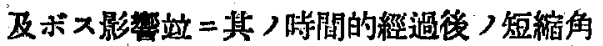

Z.T. $12-15^{\circ} \mathrm{C} \quad \mathrm{PH}_{1}=6.2-6.4$.

\begin{tabular}{|c|c|c|c|c|c|c|c|c|c|c|c|c|c|}
\hline \multirow{2}{*}{\multicolumn{2}{|c|}{ 花榆䢸紷 }} & \multirow{2}{*}{$\begin{array}{l}\text { 抽出 } \\
\text { 液人 } \\
\text { 製法 }\end{array}$} & \multirow{2}{*}{$\begin{array}{c} \\
\\
\end{array}$} & \multirow{2}{*}{ 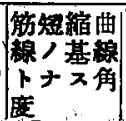 } & \multirow{2}{*}{ S緸過洔間 } & \multicolumn{7}{|c|}{ 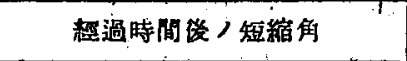 } & \multirow{2}{*}{ 學 } \\
\hline & & & & & & $\sigma^{\prime}$ & $10^{\prime}$ & $20^{\prime}$ & $30^{\circ}$ & $40^{\prime}$ & $50^{\prime}$ & $60^{\prime}$ & \\
\hline 華 & $\begin{array}{l}\text { (a) } \\
\text { (b) } \\
\text { (c) } \\
\text { (d) }\end{array}$ & 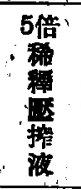 & 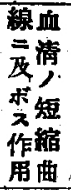 & $\begin{array}{l}35^{\circ} \\
34^{\circ} \\
52^{*} \\
53^{a}\end{array}$ & 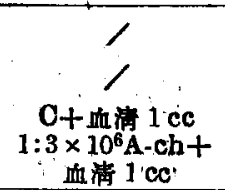 & " & $53^{\circ}$ & $\begin{array}{c}52^{\circ} \\
42^{\circ}\end{array}$ & $\begin{array}{l}49^{\circ} \\
25^{\circ}\end{array}$ & $i$ & $\begin{array}{r}45^{\circ} \\
.5^{\circ}\end{array}$ & $43^{\circ}$ & $\begin{array}{l}\text { Oortinellus- } \\
\text { shijtake }\end{array}$ \\
\hline 革 & $\begin{array}{l}\text { (a) } \\
(\mathrm{b}) \\
(\mathrm{c}) \\
(\mathrm{d})\end{array}$ & 同 & $\begin{array}{l}\text { 同 } \\
\vdots \\
\text { 上 }\end{array}$ & $\begin{array}{l}64^{\circ} \\
63^{\circ} \\
70^{\circ} \\
70^{\circ}\end{array}$ & 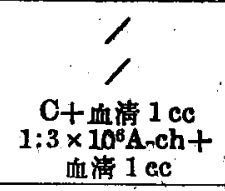 & & $68^{\circ}$ & ' & \begin{tabular}{c|} 
\\
$\therefore$ \\
$69^{\circ}$ \\
$20^{\circ}$
\end{tabular} & - & $\begin{array}{c}6 \\
69^{\circ} \\
0^{\circ}\end{array}$ & $\therefore$ & $\begin{array}{l}\text { Armillaria- } \\
\text { matsudake }\end{array}$ \\
\hline $\begin{array}{l}\hbar \\
⿱ \\
\hbar \\
\ddots\end{array}$ & $\begin{array}{l}\text { (a) } \\
\text { (b) } \\
\text { (c) } \\
\text { (d) }\end{array}$ & 上 & 同 & $\begin{array}{l}31^{\circ} \\
31^{\circ} \\
34^{\circ} \\
35^{\circ}\end{array}$ & $\begin{array}{c}C \\
\mathrm{C}+\text { 血清 } 0.7 \mathrm{cc} \\
1: 4 \times 10^{6} \mathrm{~A}-\mathrm{ch}+ \\
\text { 血清 } 0.7 \mathrm{cc}\end{array}$ & & $\begin{array}{c}34^{\circ} \\
40^{\circ}\end{array}$ & & $\begin{array}{c}\vdots \\
33^{\circ} \\
9^{\circ}\end{array}$ & 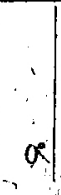 & $34^{\circ}$ & $35^{\circ}$ & $\begin{array}{l}\text { Russula- } \\
\text { virescens }\end{array}$ \\
\hline
\end{tabular}

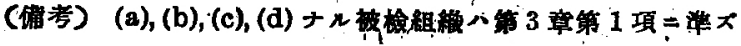

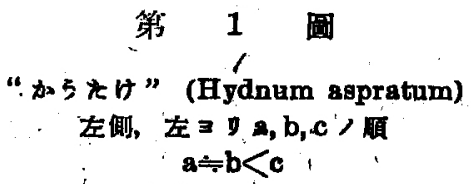

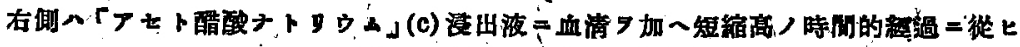
減少七ル.

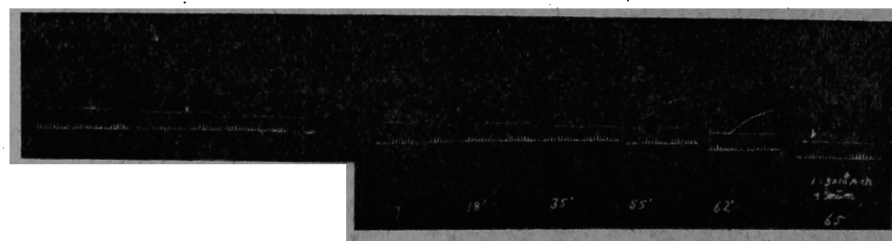

"あるたけ" (Rugsula Virescens)

上尚へ在 $a \geqslant a, b, c, d>$ 目 $a \leftarrow b<c<d$

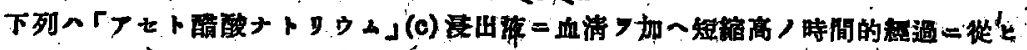

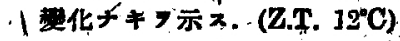

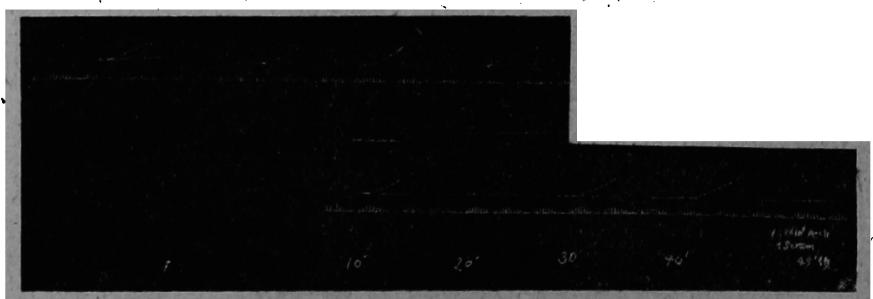


第2 2 節，温度二侬几资验

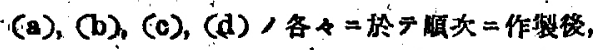

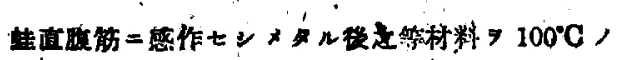

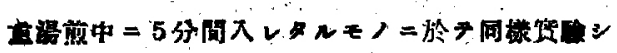

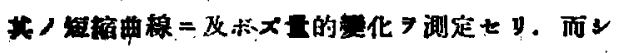

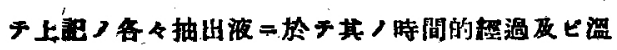

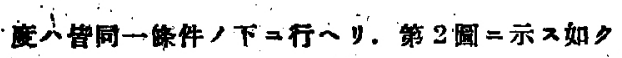

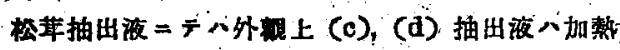

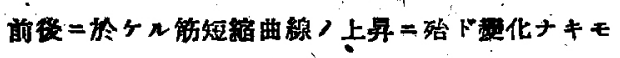

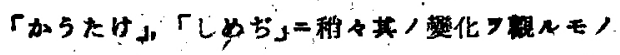

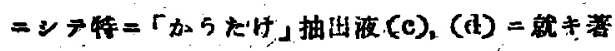

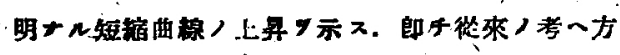

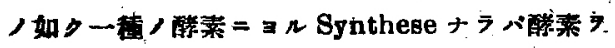

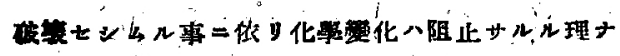

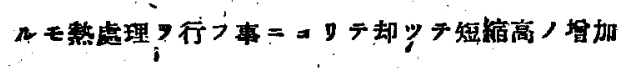
ア示七ョ.|即チ植物組維中ニデモ cholin ト Nat.

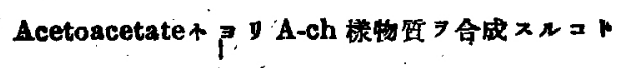

\section{第 2 圆}

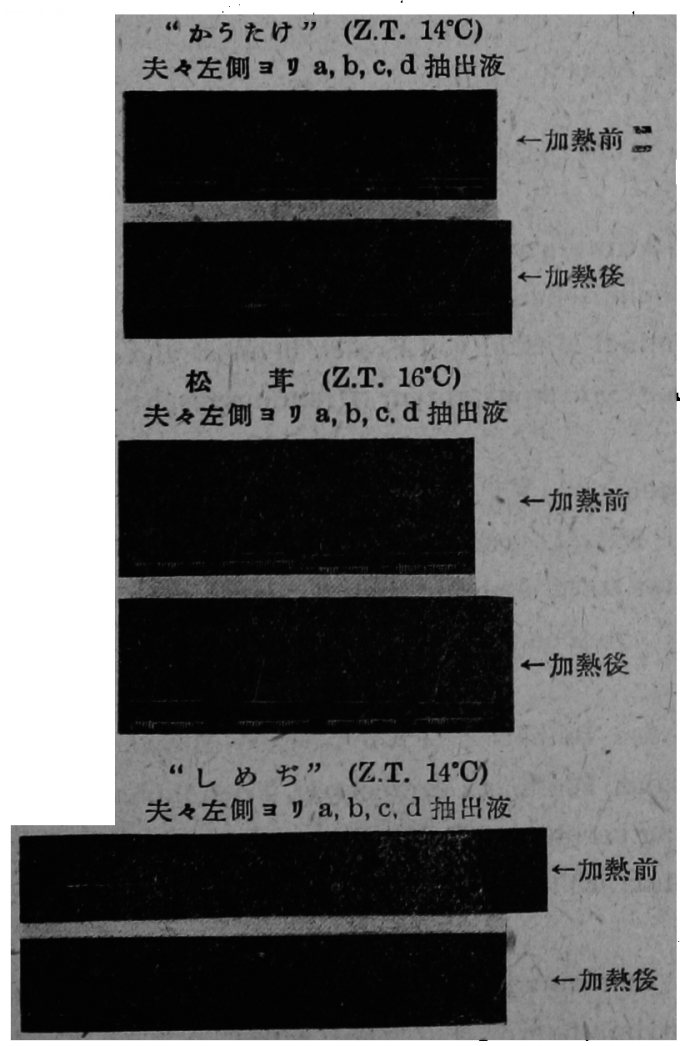

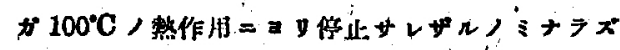

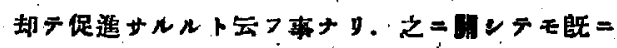

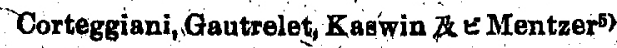

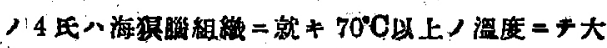

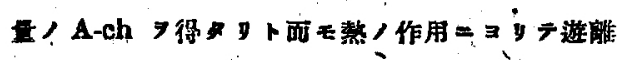

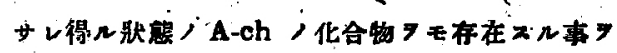

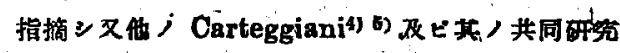

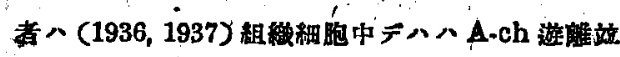

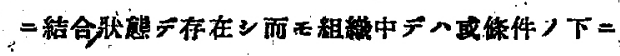

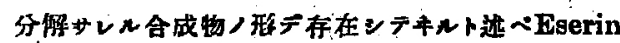

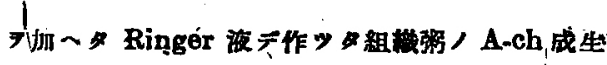

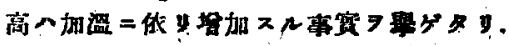

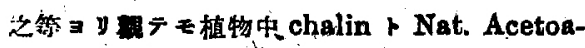

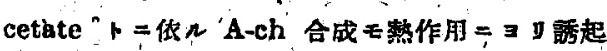
サヘモノナリト思僬ス。

\section{策4草结論}

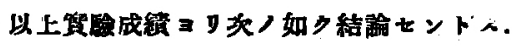

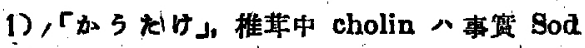

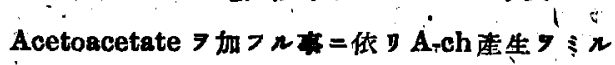

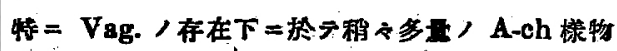

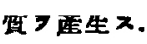

・2) しめち，あるたけ，炕らたけ，松革等 cholin $\frown$. Sod. Acetoscetate $=$ 数 $テ$ A-ch 合 成不可能艾

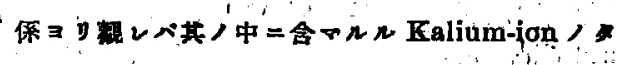

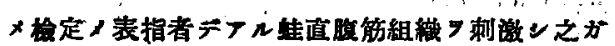

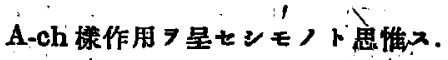

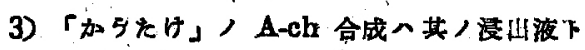
Nat. Acetoacetate 㳸液 $7100^{\circ} \mathrm{C}=$ 熱 $ス ル コ ト$ ニョリ促進セアル.

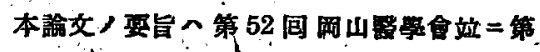
20 国日本生理學會席占テテ登表七

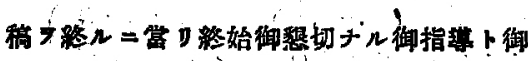

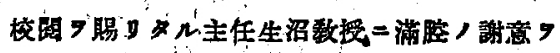
擈グ. 
I) Beąnak, J. of phyaiol. 82.,129. 1934. 2) Cicurdo \& Moglia, Nature. 145, 551, $1940 . \quad 3)$ Corteggiani, E. C. R. Soc. Biol. 124. 1197, 1937. 125, 944, 1937. 4) Corteggiani, Gautrelet, Kaswin \& Mentzer., C. R. Soc. Biol. Paris. 123. 664, 667, 1936. 5) Corteggiani, Gautrelet Gentil \& Kaswin, C. R. Soc. Biol. 125, 945,-1937. B) Feldberg \& Guimaris, J. of phyiol. 86. 306. 1936. 7) Éamk, Practical phyøiol. Chem. P. 374. 8) Kiessel, Zeit. physiol. Chem. 53, 215, 1907. 9) Lowei u. Navrutil, Pflüger،s Arch. 214, 678, 689,
1926. 10) Mendgl, Nature. 144. 479. 1939, 11) Quastel, Tennenbarm, Whealley, Biochem. J.30, 1668, 1936. 12) Scheiner, C. R. Soc. Biol. 130, 748, 1939. 13) Stedman, E. \& Stedman, E., Biö̌chem. J, 31, 817, 1937. 11) Stedman, E. \& Stedman, E., Ebenda. 29, 2107, 1935. ' 15) Schulze, Zeit. physiol. Chem. 9, 420. 1886. 16) Steidlie, Biochem. Zeit. 151, 181, $1924 . \quad$ 17) Stanek, Zeit. physiol. Chem. 46, 282, 1905, 47, 83,1905 . 18）吉村，東京化学會誌，第35卷. 19) 高澓，植物成分八研究。

\section{Aus dem 'Physiologischen Institut der Medizinischen Falcultä́t Okayama. (Vorstand: Prof. Dr. S. Oinuma) \\ Über die Azetylcholinsynthese im Extrakt aus den einigen japanischen essbaren Pilzen.}

Von

Yutaka Akaeda.

Eingegangen am 8. September 1942.

Der Verfasser hat einige experimentelle Untersuchung über die Synthese des Azetylcholins (A.Ch.) im Extrakt aus unseren einheimischen Pilzen angestellt. Dabei hat er als der Indikator für A.Ch. der geraden abdominal Muskel von Frosch benutzt und die Kontraktion dieses Muskels am Kymographion mit konstantem Drehungsgeschwindigkeit aufaeichnen lässt.

Die Resultate lassen sich folgendermassen.

1) Die Synthese des A.Ch. findet im Extrakt von Hydnum aspratum, Cortinellus Shiitake unter Zufügung von Nat. Azetoazetat statt, doch mit dem Extrakte von Tricholoma Shimeji, Psalliota campestris, Russula virescens unter gleicher Behandlung keine Synthese von A.Ch. bemerkbar.

2) Die Kontraktionsgeschwindigkeit des Detektors (Froschrectus), nimmt mit folgender Reihe zu : d.h. Armillaria Matsutake, Psalliceta campestris, Tricholoma Shimoji und Russula virescens. Aber diese Wirkung beruht auf Kaliumion, welche sie enthalten.

3) Die synthetische Wirkung von Kotake-Extrakt mit Nat. Azetoazptat wird durch das Sieden der Lösung gesteigert.

4) Nach der etwa 5 Minuten langen Erwärmung auf : $100^{\circ} \mathrm{C}$ ruft die Azetylcholin8ynthese durch Cholin und Essigeäurem Natriumihervor. (Autoreferat) 